\title{
Understanding Reasons for HIV Late Diagnosis: A Qualitative Study Among HIV-Positive Individuals in Amsterdam, The Netherlands
}

\author{
Maarten Bedert ${ }^{1}$ (D) Udi Davidovich ${ }^{2} \cdot$ Godelieve de Bree $^{3} \cdot$ Ward van Bilsen $^{4} \cdot$ Ard van Sighem $^{5} \cdot$ Wim Zuilhof $^{6}$. \\ Kees Brinkman ${ }^{7} \cdot$ Marc van der Valk $^{8} \cdot$ John de Wit $^{9}$
}

Accepted: 18 March 2021 / Published online: 31 March 2021

(c) The Author(s) 2021

\begin{abstract}
Since the introduction of effective anti-retroviral therapy, early diagnosis and treatment of HIV have become increasingly important from individual and public health perspectives. People who are diagnosed with a CD4 count below 350 cells $/ \mu \mathrm{L}$ blood are today considered to be "late" diagnoses. In an effort to understand the reasons for late diagnosis, we conducted in-depth interviews $(n=14)$ in Amsterdam, the Netherlands. Two main factors were identified: psychosocial factors and health-system factors. Psychosocial factors relate to people's personal relationship with health professionals, low risk perception, fear related to the outcome of testing, and trauma from observed past experiences of living with HIV. Health-system factors relate to institutional barriers and missed opportunities during client-provider interactions. We conclude that in order to mitigate late diagnosis, the social and institutional context within which HIV testing is conducted should be addressed.
\end{abstract}

\section{Resumen}

Desde la introducción de la terapia antirretroviral eficaz, el diagnóstico temprano y el tratamiento del VIH ha aumentado en importancia desde las perspectivas individuales y de salud pública. Personas que son diagnosticadas con VIH y que tienen un conteo de CD4 menor de 350 células/ $\mu \mathrm{L}$ de sangre, se consideran de diagnóstico "tardío". En un esfuerzo por comprender las razones de este diagnóstico tardío del VIH, realizamos entrevistas en profundidad ( $n=14)$ en Amsterdam, Países Bajos. Se identificaron dos factores principales: factores psicosociales y factores relacionados con el sistema de salud. Los factores psicosociales incluyen la relación entre el paciente y los profesionales de la salud, la baja percepción del riesgo, el miedo relacionado con el resultado de la prueba de VIH y el trauma luego de observar experiencias pasadas de personas que padecen VIH. Los factores relacionados con el sistema de salud incluyen las barreras institucionales y las oportunidades perdidas durante las interacciones entre el cliente y el proveedor de salud. Concluimos que, para mitigar el diagnóstico tardío, se deben abordar los contextos sociales e institucionales dentro de los cuales se realiza la prueba de VIH.

This study is part of the HIV Transmission Elimination Amsterdam Initiative (H-TEAM) which aims to design and implement innovative interventions with the ultimate goal of a future with no new HIV infections.

Maarten Bedert

m.r.d.bedert@amsterdamumc.nl

1 Amsterdam UMC, Location AMC, Meibergdreef 9, 1105 AZ Amsterdam, The Netherlands

2 Department of Infectious Diseases, Public Health Service Amsterdam, Amsterdam, The Netherlands

3 Amsterdam UMC, Location AMC, Amsterdam, The Netherlands

4 Public Health Service Amsterdam, Amsterdam, The Netherlands
5 Foundation HIV Monitoring, Amsterdam, The Netherlands

6 SOA AIDS Nederland, Amsterdam, The Netherlands

7 Onze Lieve Vrouwenziekenhuis, Amsterdam, The Netherlands

8 Amsterdam UMC, Location AMC \& DC Klinieken Valeriusplein, Amsterdam, The Netherlands

9 Utrecht University, Utrecht, The Netherlands 


\section{Introduction}

Recent advances in anti-retroviral therapy (ART) underscore the importance for people with HIV to be diagnosed and start HIV-treatment as early as possible [1, 2]. Early detection and entry into care have significant benefits, both for the HIV positive individual and for public health. Notably, an early start of treatment is better for a person's individual health [3-6], is cost-effective [7, 8], increases life expectancy and decreases the likelihood of onward transmission [9, 10]. Current international guidelines stipulate that treatment should start immediately upon diagnosis, irrespectively of CD4 cell count, which was previously used as a criteria to commence ART [1]. HIV diagnoses of people with a CD4 count of 350 cells/ $\mu \mathrm{L}$ or lower, or in the presence of an AIDS-defining illness, are now considered late diagnoses [11].

In 2019, half of all new infections in Europe for which a CD4 count was available were late diagnoses [12]. In the Netherlands, by the end of 2019, 23,700 people were estimated to be living with HIV [13]. That year, $48 \%$ of people newly diagnosed with HIV were considered late diagnoses. Epidemiological data from the Netherlands show that people who are diagnosed late constitute a highly diverse group [14-17], including heterosexual men and women, as well as those who perceive themselves as belonging to an older generation of men who have sex with men (MSM). Previous research found late diagnosis in the Netherlands to be associated with older age and a migration background from low and middle income countries [18-20]. Late diagnosis was also found to be more likely at hospitals, general practice clinics and antenatal screening sites, compared to sexual health clinics [14].

To better understand late diagnosis of HIV, qualitative studies have been conducted in various parts of the world [16, 19, 21-26]. These studies identified both individual and social-structural explanations for late diagnosis, including the continuing influence of stigma, personal risk assessments, fear of a positive test result, as well as a lack of provider-initiated testing. Although these earlier studies provide important insights into the possible reasons for late diagnoses, these cannot necessarily be translated to other settings.

To date no research has been published that examined reasons for late diagnosis in the Amsterdam metropolitan region, where $22 \%$ of all new HIV diagnosis in the Netherlands in 2019 occurred. Sufficient information to establish late diagnosis was available for 103 of a total of $123 \mathrm{HIV}$ diagnoses in Amsterdam in 2019, of which $43 \%$ were considered late diagnoses [13]. A further breakdown showed that $30 \%$ of MSM, $60 \%$ of women and $73 \%$ of heterosexual men were diagnosed late [13]. While the percentage of late diagnoses in Amsterdam is lowest in MSM, this constitutes is the largest group, as about two thirds (64\%) of annual HIV diagnoses in Amsterdam are among MSM. Furthermore, a national survey in the Netherlands, conducted in 2018, found that of participating MSM residing in Amsterdam, 28\% had tested for HIV longer than six months ago and 8 percent had never taken an HIV test [27]. MSM are however not a main target group for efforts to reduce late diagnosis in the Netherlands, as health professionals assume they are well informed and test regularly [28].

Amsterdam is a Fast Track City, and the HIV Transmission Elimination AMsterdam (H-TEAM) initiative combines various innovative interventions to prevent transmission of the virus by promoting prevention, earlier HIV testing and immediate treatment of infections. (see www.hteam.nl). The present study serves as an elicitation study for the development of a public health intervention to reduce late diagnoses in the Amsterdam metropolitan region, as part of the H-TEAM initiative. The aim of this study was to gain a better understanding of the reasons why people who were diagnosed with advanced HIV-infection did not test earlier for HIV. Through in-depth interviews, we examined the first-person perspectives of those who received their diagnosis in a late stage.

\section{Methods}

\section{Study Design and Population}

Between May 2019 and February 2020, we undertook a qualitative study consisting of in-depth interviews with people who received a late diagnosis. Inclusion criteria were: an HIV diagnosis in the last five years, residency in Amsterdam, a minimum age of 18 years, and CD 4 count $\leq 350$ cells/ $\mu \mathrm{L}$ at the time of diagnosis or a testing history when a CD4 count was not available. The five year cut-off for HIV diagnosis was intended to increase the likelihood that people were still in care in Amsterdam.

Given the epidemiology of HIV in the Netherlands, the focus of the study was on MSM, who are the primary group affected by HIV in the Netherlands, and people who migrated from countries with a high HIV prevalence in the general population, who constitute the second-most affected population group. For each of these key population groups, we aimed to include a diverse sample of people who were diagnosed late. We continued participant inclusion until thematic saturation was reached, separately for MSM and non-MSM.

\section{Participant Recruitment}

Participants $(n=12)$ were primarily recruited from three large HIV treatment centers in Amsterdam: a university hospital (Amsterdam University Medical Centers, 
Location Amsterdam Medical Center), a general hospital (Onze Lieve Vrouwe Gasthuis, Locatie Oost) and a private clinic (DC Klinieken). HIV specialist nurses at each of the participating treatment centers were securely provided with confidential information on eligible participants receiving HIV care at their site. With prior informed consent, this information was extracted from the national clinical database of people living with HIV in the Netherlands, which includes information on CD4 count at the time of entry into care. HIV specialist nurses contacted potential participants to inform them about the study and its procedures. If participants were interested in participating, the lead author (MB) contacted interested participants, who provided initial permission by phone or email.

In addition, we recruited 2 participants through two community organizations: the Dutch association of people with HIV (Hiv Vereniging Nederland, HVN), and Shiva, a peer support organization for people with HIV with a migration background. Information on CD4 count was not available for participants recruited through community organizations. We did however have information on their HIV testing and medical history, which was obtained during the initial phone contact.

All participants received extensive study information ahead of the interview, including about the aim of the study, the voluntary nature of participation, the possibility to withdraw and stop the interview, and the option to refuse to answer questions. Participants provided informed consent orally prior to the interview.

\section{Interviews}

Semi-structured, face-to-face interviews were conducted by MB. Interviews were guided by an open-ended topic list based on an extensive literature review to identify reasons for late diagnosis in various settings. Interviews focused on the motivation for HIV testing, and the interview tool was pre-tested among people living with HIV who did not participate in the interviews through which data were collected. The term "late presenter" was not used during the interviews, to avoid potential stigma from this health care provider centered term. Interviews were conducted in Dutch, English or French and lasted between 35 and 65 min. Interviews were conducted subsequent to a regular HIV consultation at the hospital, at a later time at the Amsterdam Public Health Service in Amsterdam or at people's homes, as participants preferred. The interviews were audio recorded and transcribed verbatim.

\section{Sample and Characteristics}

We were able to include and interview 14 people with a late diagnosis, consisting of 11 men and 3 women. Of the men,
Table 1 Sociodemographic characteristics of study participants

\begin{tabular}{lll}
\hline Variable & Categories & Number $(\%)$ \\
\hline Age & $25-35$ & $4(28.5)$ \\
& $35-45$ & $2(14.2$ \\
& $45-55$ & $4(28.5)$ \\
Region of Origin & $55-65$ & $4(28.5)$ \\
& Netherlands & $6(42.8)$ \\
& Sub Saharan Africa & $3(21.4)$ \\
& Caribbean & $3(21.4)$ \\
& Eastern Europe & $1(7.1)$ \\
Gender & Oceania & $1(7.1)$ \\
Sexual Orientation & Male & $11(78.5)$ \\
& Female & $3(21.4)$ \\
Participant Category & MSM & $8(57.1)$ \\
& heterosexual & $6(42.8)$ \\
& Dutch MSM & $6(42.8)$ \\
& Migrant MSM & $2(14.2)$ \\
& Migrant-female (straight) & $3(21.4)$ \\
& Migrant male (straight) & $3(21.4)$ \\
\hline
\end{tabular}

8 identified as MSM. Of all participants, 8 had a migration background (3 from Sub Saharan Africa, 3 from the Caribbean, 1 from Eastern Europe and 1 from Oceania; all were first-generation migrants). The main reasons given for not participating were that the person had not come to terms with the diagnosis or was concerned to discuss his or her HIV status.

For 5 participants, the initiative to test came from a health care provider as the participant showed physical (AIDS related) symptoms. Four participants were motivated by friends or family members to take a test. In other cases, testing occurred following partner notification, as part of immigration procedures, or in relation to enrolment in an HIV-related public health project (one participant each). Participants' sociodemographic characteristics are shown in Table 1; the median age of participants was 46 years (range 26-64 years).

\section{Data Analysis}

Data analysis was guided by the principles of inductive thematic content analysis. Transcripts were coded by one researcher (MB), using open coding supported by MaxQDA software. Coding was done in parallel to conducting the interviews. Categories were induced from individual codes by two researchers (MB and UD), from which analytical themes emerged.

\section{Statement on Ethics}

The study protocol was considered by the Medical Ethical Committee of the Amsterdam University Medical Centers, 
Location Academic Medical Center, and was granted an exemption from further assessment under the Medical Research Involving Human Subjects Act (WMO) of the Netherlands. All transcripts were anonymized prior to analysis by removing all personal identifiers. Participants received a gift card to the value of $€ 20$ as reimbursement. They could withdraw from the interview at any time without any explanation.

\section{Results}

Two sets of factors emerged from the data that influenced HIV testing: internal/psychosocial factors, and external/health system factors. Psychosocial factors related to perceptions of health and risk, and fears associated with HIV testing. Health system factors related to institutional barriers. In each of the interviews with late presenters, a combination of factors was recorded. Reasons to put off or postpone testing, or the absence of awareness of the need to test, that emerged from an individual's narrative showed that, for instance, while at one point in time health system factors were most salient, at another time psychosocial factors could be more prominent.

\section{Psychosocial Factors}

Three main psychosocial factors were identified: problematic communication with the primary health care provider, notably general practitioners (GPs), perceived low risk of HIV infection among MSM, and high levels of fear of the clinical and psychosocial consequences of an HIV diagnosis.

\section{Problematic Communication with GP}

Both MSM and non-MSM experienced the interpersonal relationship with their GP as a significant factor in the delay of HIV testing. Much of this delay was a result of avoiding to discuss HIV with their GP. Reasons for avoiding such discussion for MSM included concerns regarding acceptance of their sexual identity and sexual practices by the medical professional. Some MSM therefore felt unable to bring up possible health issues associated with gay sex: "For a GP, I can imagine it is difficult to bring up HIV [...] My GP was not well aware of gay-related issues" (Dutch MSM, 64). Others encountered practical issues, such as a change in doctor because of moving to a new town: "I can't blame this man, I just moved and had a new GP. I came to him with vague complaints. You probably won't tell a new patient: "go take an HIV test" (Dutch MSM, 49).

\section{Perceived Low Risk of HIV Infection}

From interviews with MSM it was clear that they mostly were aware of HIV transmission risks and protective sexual practices. Some late diagnosed MSM had even previously tested for HIV following sexual risk: "I had the suspicion I got infected. I think I got tested too early so the test turned out negative. I thought, "then it's okay'” (Dutch MSM, 47).

Among MSM, we found that risk was appraised in three different ways in relation to testing behavior: it was accepted, minimized or rationalized. The acceptance of risk refers to the ways in which MSM considered it an integral part of being sexually active or as part of particular sexual practices: "If you do bare sex, you know the risks involved" (Dutch MSM, 49). Minimization of risk occurred when people (mis) perceived their behavior as low risk, including their reference to their practicing of safer sex: "Most of the time, we have safe sex, so you tell yourself "it will be okay"' (Dutch MSM, 60); or to a lack of recent sexual activity: "I didn't test because I didn't have unprotected sex with anyone" (Migrant MSM, 27). Perceived low risk was also a reason to stop regular testing. Rationalization of risk occurred in relation to feeling healthy, an absence of physical symptoms was used as a rationale for assuming no infection had occurred: "I never felt sick after contracting the virus [...] so there was no reason for me to get tested" (Dutch MSM, 26). Among MSM, the adage was prevalent that, as long as they did not know for sure (i.e. did not get tested), they did not have HIV.

Non-MSM also indicated that a lack of symptoms played an important role in their decision not to test (again). The absence of symptoms was the reason people were not concerned about ill health and most non-MSM interviewees could not recall they experienced symptoms of acute infection. More generally, they could not trace back the (exact) time of infection or identify the person who had passed on HIV: "I don't know where it came from." (Male, Migrant, non-MSM, 63).

\section{Fear of the Consequences of HIV Infection}

Fear of potential consequences of HIV was mentioned by MSM and non-MSM alike, despite knowledge of the availability of effective treatment. One man declared "I know a woman [...] who has it. [...] She takes tablets every day, you know" (Male, Migrant non-MSM, 43). Still, following news of his own diagnosis, he vowed never to tell his family. Among non-MSM, fear was especially brought up in relation to the expectation of stigma and discrimination, and in light of the public perception of HIV. Even following diagnosis, many participants continued to be fearful of potential disclosure to sex partners, colleagues, or health workers and did not share their status beyond a small circle of well-known and trusted friends or family members: "There is no need to discuss [my diagnosis] with anybody. Nobody can help me, apart from the doctors. So there is no need to [share] my problems" (Male, Migrant non-MSM, 63). 
Fear of social stigma was in particular mentioned by people with a migration background, as they often lived in tightknit communities with much social control: "if you have HIV, they say you slept with a lot of men, that you are not serious" (Female, Migrant non-MSM, 34). Similar experiences were mentioned by MSM for whom HIV also continued to be linked to perceived immoral sexual behavior, such as having higher numbers of partners: "it came as a shock to my mother. [...] look, I can have a steady relationship but I also had a lot of casual contacts, but to explain that to your mother is difficult" (Dutch MSM, 51).

For 7 out of $8 \mathrm{MSM}$, fear emerged in relation to earlier traumatic experiences of HIV, despite being aware of new developments in treatment. Fear of the consequences of HIV and earlier trauma were mostly mentioned by those MSM who identified as belonging to an older generation. They recalled negative experiences from the early days of HIV and AIDS, when treatment was not available or had serious side-effects, and when friends and partners languished. These experiences made an indelible impression: "I have always been afraid of the test [...] in the 1990s, so many said, I don't want to know.[...] That has stayed with me" (Dutch MSM, 51). These experiences formed a general stance of denial that can be paraphrased as "if I don't know, I don't have it".

\section{Health system factors}

Our interviews revealed that those diagnosed late were not averse to testing. Instead, two main health system factors were identified that prevented people from getting tested in a timely manner: limited health system capacity and missed opportunities.

\section{Limited Health system capacity}

A first factor concerns the health system capacity for HIV testing. In Amsterdam, key populations, in particular MSM, sex workers, people under the age of 25 and people who migrated from an HIV endemic region, as well as people who received a partner notification or who experienced a high risk sexual event, can test free of charge for HIV at the public STI clinic. Among MSM, the Amsterdam public STI clinic is held in high regard, as many associate HIV/STI testing with this institution: "it is designed to help people with STIs" (Dutch MSM, 26). Still, for many MSM, long waiting times were common concerns that deterred from testing, despite acknowledging having had sexual risk: "I didn't feel like going to the STI clinic [following sexual risk] to wait for a whole day. I told myself "I will go in three months" (Dutch, MSM, 60). In addition, other barriers for testing at the STI clinic presented themselves among MSM: some erroneously thought they were non-eligible for testing at the STI clinic, and therefore (unnecessarily) felt excluded, as mentioned by this Dutch MSM [49]: "At one point, the GGD [public sexual health clinic] only became available for young people and sex workers". Others, who did not meet the criteria of the free-of-charge STI clinic, indicated they had to lie to get an appointment: "You fill in the website and it says "you don't belong to the risk group" [...] I thought: I will just lie about my condom use. But still, I couldn't get in" (Dutch MSM, 64).

\section{Missed Opportunities}

A second health system factor, noted by both MSM and nonMSM, reflects missed opportunities for HIV during past engagement with health care services, including from GPs. Many of those diagnosed late had consulted with medical care providers before their eventual HIV diagnosis. Some doctors misclassified HIV-related symptoms or AIDSdefining illnesses and missed the opportunity for diagnosis: "They have blinders on, also the GP, he later apologized for this but he never considered HIV" (Dutch MSM, 64). In other cases, HIV infection was considered a possibility, but at the time this was not pursued further with the patient. One interviewee reported how a medical specialist admitted that he had suspected HIV before, but was afraid to bring this up as he considered this a sensitive issue. Participants typically did not express anger or frustration regarding these missed opportunities. Instead, they articulated their understanding by acknowledging and accepting existing stigma: "it is a major step [for a medical professional to bring up HIV]" said one Dutch MSM participant aged 49.

\section{Discussion}

We aimed to identify factors that contribute to late diagnosis of HIV among key populations in Amsterdam, the Netherlands. From in-depth interviews, we identified psychosocial factors that contributed to late diagnosis, in particular low perceived risk of infection, including an absence of physical symptoms, and fear of the consequences of HIV infection, mostly stigma and discrimination, as well as health system factors, in particular the perceived limited accessibility of public HIV testing facilities, and potential missed opportunities for HIV testing. What is most prominent in our findings is that HIV continued to be considered as exceptional by people diagnosed late as well as by their health care providers [29-33], indicating the high threshold in discussing the topic, both in health care and private settings and among MSM as well as non-MSM.

Among late diagnosed MSM, interviews showed that their views and practices regarding HIV testing are strongly shaped by their historic experiences with HIV-related trauma 
and social stigma as sexual minorities. Many of the participating MSM, who identified as part of an older generation of gay men, remembered friends or partners they had lost in the early days of the HIV epidemic. These profoundly adverse experiences resulted in a sustained fear of testing HIV-positive and the rationalization of risk of infection, despite awareness of effective ART, education campaigns, and positive role models living with HIV. This finding corresponds with earlier studies among MSM within the UK which describe how biomedical advancements, in this case the emergence of the antibody test, affected perceptions of belonging to a local gay community based on knowing your status. The decision to test, these studies show, depends on whether the burden of 'not knowing' outweighed an imagined positive result [34-36]. In view of the prominence of the traumatic (collective) memory of the early HIV epidemic among older MSM, we see much potential for interventions, developed using participatory approaches, to explicitly address these earlier traumatic experiences with HIV and other entrenched barriers to HIV testing, especially perceived or internalized social stigma, to mitigate the continued experienced exceptional status of HIV.

Our study found that late diagnosed MSM and non-MSM alike, find it difficult to bring up HIV testing with their GPs themselves and express understanding for the reluctance of GPs to bring up HIV testing. More generally, many participants felt uncomfortable discussing sexual practices and risk with their GP. This problematic communication about sex, HIV and risk with GPs and other health professionals likely reflects social stigma. One study in the Netherlands found that despite claims of equal treatment, professionals, even presently, had little experience with HIV and feared occupational infection while patients complained of rude treatment, excess precautions and care refusal [37]. Furthermore, research in Australia has found that even HIV physicians themselves still consider HIV a far-from-ordinary illness [38].

As a result of the difficulty to bring up HIV during consultations, there continue to be missed opportunities for earlier diagnosis. Some participants reported that even when they sought healthcare whilst experiencing HIV related symptoms, an HIV test was never offered to them, as is also found in studies in the Netherlands [39] and abroad [40-44]. The problematic communication with health professionals and the missed opportunities for HIV testing highlight the importance of comprehensive initiatives that address the acceptance of sexual identity for MSM and the relevance of sexual experience for MSM and non-MSM as facilitators of HIV testing. Interventions to reduce late diagnoses should also include a more pro-active initiation of HIV testing by GPs, including increased uptake of indicator disease-based HIV testing [45-49], which also contributes to addressing the continued exceptional status of HIV.
Non-MSM in our study did not consider HIV as part of their social reality. They lacked adequate risk perception and consequently did not test for HIV, and a lack of physical symptoms related to HIV/AIDS was a compounding factor. As also shown by other studies, a lack of risk awareness was particularly likely among heterosexual women and men with a migration background [14]. This is somewhat unexpected for people who migrated from HIV-endemic regions, as they likely had experiences with HIV in their home country. Any such experiences did however not seem to translate into a perception of personal risk of HIV, as also noted in other research [19]. This lack of awareness or possible denial of personal HIV risk can be considered a form of distancing and othering that reinforces the continued exceptional status of HIV [50].

Participants with a migration background expressed a high degree of fear of the possible implications of an HIV diagnosis. They especially feared the consequences of their diagnosis becoming public and the social stigma they could consequently experience from members of their community, which they experienced as tight-knit. The prominence of cultural factors in the reproduction of HIV related stigma, and the related exception status of HIV, has been described by others, particularly for African and Afro-Caribbean communities in the Netherlands [51, 52].

In our study, the continued reproduction of HIV exceptionalism is a prominent, common theme that links the various psychosocial and health systems barriers to HIV testing. Whereas it has been argued that HIV can be seen as a manageable, chronic condition, thanks to advances in HIV treatment, stigma reduction campaigns, awareness raising that undetectable HIV infection means that HIV is untransmissible ( $\mathrm{U}=\mathrm{U}$ campaigns) [53, 54], our findings suggest this may not resonate with all people at risk of HIV. We found that there continues to be a disjuncture between the medical normalization of HIV and the exceptionalism of HIV in people's own experience [55-60]. Especially among older MSM, the continued and historically shaped perception of burden of disease associated with HIV requires further attention [61, 62].

As any study, ours also has limitations. Although we reached thematic saturation in our interviews, the number of participants in our study is an important limitation, as many potential participants declined participation in our study. This was also reflected upon in interviews with two specialist nurses who indicated that potential participants backed out because they feared their diagnosis would become public and would lead to increased stigma. While a methodological limitation, the reasons for this reluctance to participate underscore the continued HIV exceptionalism. Also, our study only included self-selected participants who lived in the Amsterdam metropolitan region, and we urge caution in extrapolating or generalizing findings to other settings. 
Furthermore, as data were collected using in-depth interviews, there is a potential for social desirability bias, in addition to cognitive biases that may affect the memory and recollection of past experiences.

\section{Conclusion}

The advantages of early HIV diagnosis and early initiation of HIV treatment are well established, and the biomedical tools to achieve this are available. Our study however finds various factors that present barriers for timely HIV testing and diagnosis among MSM and non-MSM at risk of HIV in Amsterdam. Our data in particular underscore that an HIV diagnosis remains concerning and exceptional for some of those at risk, both MSM and non-MSM, and the anticipated adverse social impact and health burden of an HIV diagnosis contribute to late diagnosis. Our findings also highlight health systems barriers that might lead to missed opportunities for timely HIV testing and diagnoses, which involve unrecognized or minimized risk of HIV among MSM as well as non-MSM, perceiving HIV as exceptional resulting in an unease in bringing up HIV testing on the part of people at risk and professionals. Collectively, the diversity of experiences of participants suggest that more information about advances in HIV treatment will not play a decisive role in promoting HIV testing and will not necessarily contribute to preventing late diagnoses. Rather than individual-focused approaches to promote risk awareness and personal initiative regarding HIV testing, interventions are needed that focus on promoting an enabling social and healthcare context within which HIV risk awareness and HIV testing are normalized for health care providers and people at risk alike.

Open Access This article is licensed under a Creative Commons Attribution-NonCommercial 4.0 International License, which permits any non-commercial use, sharing, adaptation, distribution and reproduction in any medium or format, as long as you give appropriate credit to the original author(s) and the source, provide a link to the Creative Commons licence, and indicate if changes were made. The images or other third party material in this article are included in the article's Creative Commons licence, unless indicated otherwise in a credit line to the material. If material is not included in the article's Creative Commons licence and your intended use is not permitted by statutory regulation or exceeds the permitted use, you will need to obtain permission directly from the copyright holder. To view a copy of this licence, visit http://creativecommons.org/licenses/by-nc/4.0/.

\section{References}

1. Panel on Antiretroviral Guidelines for Adults and Adolescents. Guidelines in the Use of Antiretroviral Agents in Adults and Adolescents with HIV [Internet]. http://www.aidsinfo.nih.gov/
ContentFiles/AdultandAdolescentGL.pdf. 2020 [cited 2020 Nov 12]. Available from: https://clinicalinfo.hiv.gov/sites/default/files/ guidelines/documents/AdultandAdolescentGL.pdf

2. Initiation of Antiretroviral Therapy in Early Asymptomatic HIV Infection. N Engl J Med. 2015;373(9):795-807.

3. Chadborn TR, Baster K, Delpech VC, Sabin CA, Sinka K, Rice $\mathrm{BD}$, et al. No time to wait: how many HIV-infected homosexual men are diagnosed late and consequently die? (England and Wales, 1993-2002). AIDS. 2005;19(5):513-20.

4. Egger M, May M, Chêne G, Phillips AN, Ledergerber B, Dabis F, et al. Prognosis of HIV-1-infected patients starting highly active antiretroviral therapy: a collaborative analysis of prospective studies. Lancet. 2002;360(9327):119-29.

5. INSIGHT START Study Group, Lundgren JD, Babiker AG, Gordin F, Emery S, Grund B, et al. Initiation of antiretroviral therapy in early asymptomatic HIV infection. N Engl J Med. 2015;373(9):795-807.

6. Lanoy E, Mary-Krause M, Tattevin P, Perbost I, Poizot-Martin $\mathrm{I}$, Dupont $\mathrm{C}$, et al. Frequency, determinants and consequences of delayed access to care for HIV infection in France. Antivir Ther. 2007;12(1):89-96.

7. Krentz HB, Auld MC, Gill MJ. The high cost of medical care for patients who present late $(\mathrm{CD} 4<200$ cells $/ \mu \mathrm{L})$ with HIV infection. HIV Med. 2004;5(2):93-8.

8. Krentz HB, Gill MJ. The direct medical costs of late presentation $(<350 / \mathrm{mm})$ of HIV infection over a 15 -year period. AIDS Res Treat. 2012;2012:757135.

9. Cohen MS, Chen YQ, McCauley M, Gamble T, Hosseinipour MC, Kumarasamy N, et al. Antiretroviral therapy for the prevention of HIV-1 transmission. N Engl J Med. 2016;375(9):830-9.

10. Marks G, Crepaz N, Janssen RS. Estimating sexual transmission of HIV from persons aware and unaware that they are infected with the virus in the USA. AIDS. 2006;20(10):1447-50.

11. Antinori A, Coenen T, Costagiola D, Dedes N, Ellefson M, Gatell J, et al. Late presentation of HIV infection: a consensus definition: Consensus definition of late presentation. HIV Med. 2011;12(1):61-4.

12. European Centre for Disease Prevention and Control, WHO Regional Office for Europe. HIV/AIDS surveillance in Europe 2020-2019 data [Internet]. Copenhagen: WHO Regional Office for Europe; 2020 [cited 2021 Jan 8]. Available from: https:// www.ecdc.europa.eu/sites/default/files/documents/hiv-surve illance-report-2020.pdf

13. van Sighem A, Wit F, Boyd A, Smit C, Matser A, Reiss P, Human Immunodeficiency Virus (HIV) infection in the Netherlands. Amsterdam: Stichting HIV Monitoring; 2020. p. 2020.

14. de Coul ELMO, van Sighem A, Brinkman K, van Benthem BH, van der Ende ME, Geerlings S, et al. Factors associated with presenting late or with advanced HIV disease in the Netherlands, 1996-2014: results from a national observational cohort. BMJ Open. 2016;6(1):e009688.

15. Op de Coul ELM, Schreuder I, Conti S, van Sighem A, Xiridou M, Van Veen MG, et al. Changing patterns of undiagnosed HIV infection in the Netherlands: who benefits most from intensified HIV test and treat policies? Clark JL, editor. PLoS ONE. 2015;10(7): 0133232

16. van Opstal SEM, van der Zwan JS, Wagener MN, Been SK, Miedema HS, Roelofs PDDM, et al. Late presentation of HIV infection in the Netherlands: reasons for late diagnoses and impact on vocational functioning. AIDS Behav. 2018;22(8):2593-603.

17. van Veen $M$, Trienekens S, Heijman T, Gotz H, Zaheri S, Ladbury G, et al. Delayed linkage to care in one-third of HIVpositive individuals in the Netherlands. Sex Transm Infect. 2015;91(8):603-9. 
18. Alvarez-del Arco D, Monge S, Azcoaga A, Rio I, Hernando V, Gonzalez C, et al. HIV testing and counselling for migrant populations living in high-income countries: a systematic review. Eur J Pub Health. 2013;23(6):1039-45.

19. Burns FM, Imrie JY, Nazroo J, Johnson AM, Fenton KA. Why the(y) wait? Key informant understandings of factors contributing to late presentation and poor utilization of HIV health and social care services by African migrants in Britain. AIDS Care. 2007;19(1):102-8.

20. Fakoya I, Álvarez-del Arco D, Copas AJ, Teixeira B, Block K, Gennotte A-F, et al. Factors associated with access to HIV testing and primary care among migrants living in Europe: crosssectional survey. JMIR Public Health Surveill. 2017;3(4):e84.

21. Assen A, Molla F, Wondimu A, Abrha S, Melkam W, Tadesse E, et al. Late presentation for diagnosis of HIV infection among HIV positive patients in South Tigray Zone, Ethiopia. BMC Public Health. 2016;12:16.

22. Dowson L, Kober C, Perry N, Fisher M, Richardson D. Why some MSM present late for HIV testing: a qualitative analysis. AIDS Care. 2012;24(2):204-9.

23. Moshabela M, Bukenya D, Darong G, Wamoyi J, McLean E, Skovdal M, et al. Traditional healers, faith healers and medical practitioners: the contribution of medical pluralism to bottlenecks along the cascade of care for HIV/AIDS in Eastern and Southern Africa. Sex Transm Infect. 2017;93(Suppl 3).

24. Nelson KM, Thiede H, Hawes SE, Golden MR, Hutcheson R, Carey JW, et al. Why the wait? Delayed HIV diagnosis among men who have sex with men. J Urban Health. 2010;87(4):642-55.

25. Nelson KM, Thiede H, Jenkins RA, Carey JW, Hutcheson R, Golden MR. Personal and contextual factors related to delayed HIV diagnosis among men who have sex with men. AIDS Educ Prev. 2014;26(2):122-33.

26. Sikstrom L. "There was no love there": Intergenerational HIV disclosure, and late presentation for antiretroviral therapy in Northern Malawi. Soc Sci Med. 2018;1(211):175-82.

27. den Daas C, Zuilhof W, Vermey K, Dorfler T, van Bijnen T, De Wit J. Rapport SMS Mannen en seksualiteit MSM Soa-Aids Nederland 2018. Utrecht: SOAAIDS; 2018.

28. den Daas C, Doppen M, Schmidt AJ, Op de Coul E. Determinants of never having tested for HIV among MSM in the Netherlands: Table 1. BMJ Open. 2016;6(1):e009480.

29. Benton A. HIV exceptionalism: development throug disease in Sierra Leone. Minneapolis: Minnesota University Press; 2015.

30. Bayer R, Fairchild AL. Changing the paradigm for HIV testingthe end of exceptionalism. N Engl J Med. 2006;355(7):647-9.

31. Smith JH, Whiteside A. The history of AIDS exceptionalism. J Int AIDS Soc. 2010;13(1):47-47.

32. Bayer R. Public health policy and the AIDS epidemic: an end to HIV exceptionalism? N Engl J Med. 1991;324(21):1500-4.

33. Moyer E, Hardon A. A Disease unlike any other? Why HIV remains exceptional in the age of treatment. Med Anthropol. 2014;33(4):263-9.

34. Flowers P, Duncan B, Knussen C. Re-appraising HIV testing: an exploration of the psychosocial costs and benefits associated with learning one's HIV status in a purposive sample of Scottish gay men. Br J Health Psychol. 2003;8(2):179-94.

35. Flowers P, Duncan B, Frankis J. Community, responsibility and culpability: HIV risk-management amongst Scottish gay men. J Community Appl Soc Psychol. 2000;10(4):285-300.

36. Flowers P. Gay men and HIV/AIDS risk management. Health (London). 2001;5(1):50-75.

37. Stutterheim SE, Sicking L, Brands R, Baas I, Roberts H, van Brakel WH, et al. Patient and provider perspectives on HIV and HIV-related stigma in Dutch Health Care Settings. AIDS Patient Care STDS. 2014;28(12):652-65.
38. Persson A, Newman CE, Hopwood M, Kidd MR, Canavan PG, Kippax SC, et al. No ordinary mainstream illness: how HIV doctors perceive the virus. Qual Health Res. 2014;24(1):6-17.

39. Joore IK, Reukers DFM, Donker GA, van Sighem AI, Op de Coul ELM, Prins JM, et al. Missed opportunities to offer HIV tests to high-risk groups during general practitioners' STI-related consultations: an observational study. BMJ Open. 2016;6(1):e009194.

40. Sudarshi D, Pao D, Murphy G, Parry J, Dean G, Fisher M. Missed opportunities for diagnosing primary HIV infection. Sex Transm Infect. 2008;84(1):14-6.

41. Burns FM, Johnson AM, Nazroo J, Ainsworth J, Anderson J, Fakoya A, et al. Missed opportunities for earlier HIV diagnosis within primary and secondary healthcare settings in the UK. AIDS. 2008;22(1):115-22.

42. Lhopitallier L, Moulin E, Hugli O, Cavassini M, Darling KEA. Missed opportunities for HIV testing among patients newly presenting for HIV care at a Swiss university hospital: a retrospective analysis. BMJ Open. 2018;8(6):e019806.

43. Brawley D, MacConnachie A, Nandwani R, Bell DJ, Fargie F, Fox R, et al. Missed opportunities for HIV diagnosis: a three-year audit in the West of Scotland. Scott Med J. 2013;58(3):173-7.

44. Helleberg M, Engsig FN, Kronborg G, Laursen AL, Pedersen $\mathrm{G}$, Larsen $\mathrm{O}$, et al. Late presenters, repeated testing, and missed opportunities in a Danish nationwide HIV cohort. Scand J Infect Dis. 2012;44(4):282-8.

45. Joore IK, Arts DL, Kruijer MJ, Moll van Charante EP, Geerlings SE, Prins JM, et al. HIV indicator condition-guided testing to reduce the number of undiagnosed patients and prevent late presentation in a high-prevalence area: a case-control study in primary care. Sex Transm Infect. 2015;91(7):467-72.

46. Deblonde J, Van Beckhoven D, Loos J, Boffin N, Sasse A, Nöstlinger C, et al. HIV testing within general practices in Europe: a mixed-methods systematic review. BMC Public Health. 2018;18(1):1191.

47. Davies CF, Kesten JM, Gompels M, Horwood J, Crofts M, Billing $\mathrm{A}$, et al. Evaluation of an educational intervention to increase HIV-testing in high HIV prevalence general practices: a pilot feasibility stepped-wedged randomised controlled trial. BMC Fam Pract. 2018;19(1): 195.

48. Joore IK, van Bergen JEAM, Ter Riet G, van der Maat A, van Dijk N. Development and evaluation of a blended educational programme for general practitioners' trainers to stimulate proactive HIV testing. BMC Fam Pract. 2018;19(1):36.

49. Joore IK, van Roosmalen SL, van Bergen JE, van Dijk N. General practitioners' barriers and facilitators towards new provider-initiated HIV testing strategies: a qualitative study. Int J STD AIDS. 2017;28(5):459-66.

50. Schiller NG, Crystal S, Lewellen D. Risky business: the cultural construction of AIDS risk groups. Soc Sci Med. 1994;38(10):1337-46.

51. Stutterheim SE, Bos AER, van Kesteren NMC, Shiripinda I, Pryor JB, de Bruin M, et al. Beliefs Contributing to HIV-related Stigma in African and Afro-Caribbean Communities in the Netherlands: Beliefs contributing to HIV-related stigma. J Community Appl Soc Psychol. 2012;22(6):470-84.

52. Stutterheim SE, Bos AER, Shiripinda I, de Bruin M, Pryor JB, Schaalma HP. HIV-related stigma in African and Afro-Caribbean communities in the Netherlands: manifestations, consequences and coping. Psychol Health. 2012;27(4):395-411.

53. Beckwith CG, Flanigan TP, del Rio C, Simmons E, Wing EJ, Carpenter CCJ, et al. It is time to implement routine, not risk-based. HIV Test Clin Infect Dis. 2005;40(7):1037-40.

54. Delpierre C, Cuzin L, Lert F. Routine testing to reduce late HIV diagnosis in France. BMJ. 2007;334(7608):1354-6. 
55. De Cock KM, Johnson AM. From exceptionalism to normalisation: a reappraisal of attitudes and practice around HIV testing. BMJ. 1998;316(7127):290-3.

56. Flowers P. HIV Transitions: Consequences for Self in an Era of Medicalisation. In: Davis M, Squire C, editors. HIV Treatment and Prevention Technologies in International Perspective [Internet]. London: Palgrave Macmillan UK; 2010 [cited 2021 Jan 8]. p. 109-25. Available from: https://doi.org/10.1057/9780230297 050_6

57. Persson A. Non/infectious corporealities: tensions in the biomedical era of 'HIV normalisation.' Sociol Health Illn. 2013;35(7):1065-79.

58. Philbin MM. "What I Got to Go Through": normalization and HIV-positive adolescents. Med Anthropol. 2014;33(4):288-302.

59. Walker L. 'There's no pill to help you deal with the guilt and shame': contemporary experiences of HIV in the United Kingdom. Health (London). 2019;23(1):97-113.
60. Mazanderani F, Paparini S. The stories we tell: Qualitative research interviews, talking technologies and the 'normalisation' of life with HIV. Soc Sci Med. 2015;1(131):66-73.

61. Bilsen WPH van, Zimmermann HML, Boyd A, Davidovich U. Burden of living with HIV among men who have sex with men: a mixed-methods study. The Lancet HIV [Internet]. 2020 [cited 2020 Nov 23];0(0). Available from: https://www.thelancet.com/ journals/lanhiv/article/PIIS2352-3018(20)30197-1/abstract

62. McDaid L, Flowers P. Pandemics have psychosocial and sociocultural burdens. The Lancet HIV. 2020;7(12):e801-2.

Publisher's Note Springer Nature remains neutral with regard to jurisdictional claims in published maps and institutional affiliations. 